\title{
Optical Coherence Tomography Angiography of Optic Disc Perfusion in Primary Open Angle Glaucoma
}

\author{
BASMA G. MOHAMED, M.Sc.; SAID M. SHALABY, M.D.; WALEED A. ALLAM, M.D. and \\ EL-SAYED A. NASSAR, M.D.
}

The Department of Ophthalmology, Faculty of Medicine, Tanta University

\begin{abstract}
Background: Glaucoma is a major disease that potentially results in irreversible blindness. Optical coherence tomography angiography (OCTA) is a novel technique for evaluation of retinal vascular changes. Using OCTA have provided useful information about the papillary and peripapillary microvasculature. Optic nerve head perfusion measurements.

Aim of Study: To investigate optic disc perfusion differences between normal and primary open angle glaucoma eyes using optical coherence tomography angiography (OCTA).

Methods: This prospective comparative cross-sectional selective pilot study was performed on 15 eyes of 15 primary open angle glaucoma (POAG) patients and 20 eyes of 20 healthy age-matched controls. OCT and OCTA were performed using swept source TOPCON 3D OPTICAL COHERENCE TOMOGRAPHY DRI OCT Triton. The optic nerve head $(\mathrm{ONH})$ was imaged with a $4.5 \times 4.5 \mathrm{~mm}$ scan and assessed in 4 different levels of segmentation; the superficial Papillary, deep papillary, outer retina level and choroidal level. Density map images gave qualitative data and quantitative assessment, these images were processed using Image J program (IJ 1.46 $r$ edition) for determining vascular density index (VDI). The Central corneal thickness, retinal nerve fiber layer thickness (RNFLT), ganglion cell layer thickness (GCLT), stereometric parameters cup/disc area, rim area, cup volume and visual field parameters [mean deviation (MD), pattern standard deviation (PSD) were tested for correlation with vascular density.
\end{abstract}

Results: The vascular density index in the OCT angiograms, as a quantitative assessment, of the optic nerve head (ONH) perfusion was significantly lower in the glaucoma group when compared with the normal age matched control groups. This reduction was significant in POAG with average VDI was reduced by $6.29 \%$. However, in qualitative assessment the dense microvascular network that was visible on OCTA in normal discs, was visibly attenuated with marked capillary drop out in subjects with glaucoma. This reduction in vascular density i.e. ischemia may have a primary element as detected by decreased VDI at choroidal level POAG that reduced by $17.37 \%$. In addition, it may be secondary to elevated IOP that has direct impact with decrease VDI at superficial papillary

Correspondence to: Dr. Basma G. Mohamed,

The Department of Ophthalmology, Faculty of Medicine,

Tanta University level that is marked in cases with high IOP. The vascular density index was correlated significantly with all functional and structural parameters and the rate of disease progression and severity.

Conclusions: OCTA may offer insights into the pathophysiology of glaucomatous damage and understanding the role of vascular factors in the pathogenesis of the disease. Hence, it may be a promising technology in glaucoma management.

Key Words: OCT angiography - VDI-Primary open-angle glaucoma.

\section{Introduction}

GLAUCOMA is a major disease that potentially results in irreversible blindness. It is the leading cause of irreversible blindness worldwide [1]

For a long period of time, elevated intraocular pressure (IOP) was recognized as the only cause of neural tissue loss at the $\mathrm{ONH}$, subsequently resulting in visual field loss [2,3]. Although elevated IOP is a major risk factor, many epidemiological studies have revealed that IOP reduction alone cannot prevent the progression of visual field loss in all patients [4]. Besides elevated IOP, a growing body of evidence has suggested that vascular factors play a critical role in the development of glaucom [5]. There is a general consensus that ocular blood flow is reduced in glaucoma and that vascular factors might be more prominent in open-angle glaucoma (OAG) [6].

Optical coherence tomography angiography (OCTA) is a new imaging technology that provides a non-invasive, high resolution, three-dimensional image of the fundus microcirculation. OCTA detects variations in the intensity and/or phase properties of the OCT signals over multiple B-scans that result from movement of blood to generate the map of the vessels $[7,8]$ 
Recent studies using OCTA have provided useful information about the papillary and peripapillary microvasculature. Optic nerve head perfusion measurements are highly repeatable and reproducible [9]. A dense microvascular network with no focal capillary dropout is observed around most healthy optic discs. Spaide et al., [10] showed that in healthy eyes, the radial peripapillary capillary network could not be visualized by fluorescein angiography, whereas the network was readily visualized in the OCTA images.

OCTA vessel density has similar diagnostic accuracy to RNFL thickness measurements for differentiating between healthy and glaucoma eyes. These results suggest that OCTA measurements reflect damage to tissues relevant to the pathophysiology of OAG. OCTA has the potential to be used as a clinical tool for glaucoma diagnosis and followup, providing vascular details that have not been previously observed by other methods [11].

The objective of the current study is to investigate optic disc perfusion differences between normal and primary open angle glaucoma eyes using optical coherence tomography angiography.

\section{Patients and Methods}

This comparative cross sectional pilot study carried out on 15 glaucomatous eyes of 15 patients diagnosed as POAG attending Tanta University Hospital and 20 normal eyes of 20 age and sex matched normal subjects from March 2017 to September 2017. Written informed consent was obtained from each subject following an explanation of the nature of the study.

This study had 2 groups; 15 glaucomatous eyes of Adult Onset High Tension POAG (AO POAG) (age of onset $>40$ years). Normal control agematched individuals: (20 eyes). Only one eye per subject was included in the study and chosen randomly.

Each subject underwent a thorough complete ophthalmological examination; including best corrected visual acuity (BCVA) using snellen chart in decimal notation and autorefractometer (Auto Ref-Keratometer ACCUREF K-900, kagawa factorY 958 IKEUCHI, KONANCHO, TAKAMATSU, KAGAWA, JAPAN), slit-lamp biomicroscopy, fundoscopy and gonioscopy using Goldmann 3 mirror contact lens.

Measurements were also IOP using Goldmann applanation tonometer, axial length (AL) IOL Master (Carl Zeiss Meditec AG, Goeschwitzer
Strasse 51-52, 07745 Jena, Germany) axial myopia with AL > 24mm were excluded and CCT using NIDEK SPECULAR MICROSCOPE 2013 (NIDEK CO., LTD. CLASS 1 LED PRODUCT CEM-530 SPECULAR MICROSCOPE, 140308, 34-14 MAEHAMA HIROISHI-CHO GAMAGORI AICHI JAPAN).

Systolic blood pressure (SBP), diastolic blood pressure (DBP) and heart rate were also measured in all subjects. Ocular perfusion pressure (OPP) was calculated from systemic and intraocular pressure measurements with the following equations: BP amplitude was calculated from systolic blood pressure (SBP) and diastolic blood pressure (DBP) according to the following formula: BP amplitude $=$ SBP-DBP. Mean arterial pressure (MAP) was calculated according to the following formula: $\mathrm{MAP}=\mathrm{DBP}+0.42$ (SBP-DBP) [12]. Ocular perfusion pressure (OPP) was calculated according to the following formula: OPP=2/3 MAP-IOP [13] .

The inclusion criteria for patients with $P O A G$ were as the following: (1) Glaucomatous optic neuropathy, defined as the presence of at least two of the following characteristics: Increased cup-todisc (C/D) ratio, C/D asymmetry >0.2, disc haemorrhage, neuro retinal rim notching or thinning consistent with glaucoma (2) RNFL defect that is visible in red free slit lamp biomicroscoy or red free fundus photography. (3) Glaucomatous visual field defects (VFDs) defined as the presence of at least the characteristic VFDs (e.g. glaucoma hemifield test result outside the normal limits ,mean defect and pattern standard deviation outside the $95 \%$ confidence limits, and acluster of at least three points with $p<0.05$ and one point with $p<0.01$ in the pattern deviation plot). (4) Open anterior chamber angles in both eyes (determined by gonioscopy ); (5) No history of other ocular or systemic disease with $\mathrm{ON}$ damage. Inclusion criteria for normal controls were: (1) IOP $<21 \mathrm{mmHg}$, (2) Normal symmetric optic nerve head $(\mathrm{ONH})$ in both eyes, (3) normal neuroretinal rim and RNFL, (4) Normal standard automated perimetry, (5) Normal apparent open angle in gonioscopic examination, (6) No evidence of retinal pathology or glaucoma, (7) No chronic systemic or ocular corticosteroid use. The exclusion criteria for all subjects were the following: (1) Any retinal disease affecting retinal vascularity as DM, HTN or retinal vasular diseases, (2) Any media opacity interfering with clinical examination or investigations (corneal opacity, mature and hypermature cataract, vitreous hemorrhage and retinal detachment), (3) Any disease that may cause VF loss or ONH abnormalities, (4) Any physical and/or mental handicapping pre- 
venting investigation or affect reliability of automated visual field testing, (5) Patients with previous ocular laser and or intraocular surgery.

\section{Visual field testing:}

Visual field testing was performed with a Humphrey Matrix field analyser full threshold programs 24-2; (Carl Zeiss Meditec, Inc, 5160 Hacienda Drive, Dubiin, CA 94568 USA). (Carl Zeiss Meditec AG, Goeschwiter Strasse 51-52,07745 Jena, Germany). All participants underwent VF testing to determine MD and PSD using the standard automated perimetry with strategy size III white stimulus at the same time with imaging. VF with more than $33 \%$ fixation losses or false-negative errors or more than $15 \%$ false-positive errors were excluded.

\section{Colored fundus photography:}

This was performed for the optic disc using Confocal scanning laser ophthalmoscopy (CSLO) that is built in TOPCON 3D OPTICAL COHERENCE TOMOGRAPHY DRI OCT Triton.

\section{Optical coherence tomography:}

The subjects underwent pupillary dilatation using tropicamide $1 \%$. Imaging was performed by the same investigator and the same machine TOPCON 3D OPTICAL COHERENCE TOMOGRAPHY DRI OCT Triton (TOPCON CORPORATION 75-1, Hasunuma-cho, Itabashi-Ku, Tokyo, Japan). The peripapillary RNFLT was measured from 12.0 $\mathrm{x} 9.0 \mathrm{~mm}$ avolumetric circular scan centered on the optic disc. Measurments of RNFL thickness were taken from the RNFL thickness circular sampling profile map $3.4 \mathrm{~mm}$ centered on the optic disc.

The mean peripapillary RNFL thickness was determined along the concentric center of the optic disc margin and the thicknesses of the four areas (superior, inferior, nasal and temporal quadrants) were also measured. Macular GCLT was also measured in 1, 3 and $6 \mathrm{~mm}$ circular profile around fovea. Macular GCLT measurments at $3 \mathrm{~mm}$ circular area and its average were included in the study.

Optical coherence tomography angiography (OCTA) of the optic disc:

OCTA were performed using swept source TOPCON 3D OPTICAL COHERENCE TOMOGRAPHY DRI OCT Triton (TOPCON CORPORATION 75-1, Hasunuma-cho, Itabashi-Ku, Tokyo, Japan) imaging system can acquire 100,000 Ascan per second. Swept Source OCT provides a significant improvement over conventional OCT as the optimized long wavelength scanning light $(1,050 \mathrm{~nm})$, there is better penetration of the deeper layers of the eye. Furthermore, this scanning light also penetrates better through cataracts, haemorrhages, blood vessels and sclera with the ability of retinal segmentation and detection of vascularity changes in different levels [14].

OCTA was performed using $4.5 \times 4.5 \mathrm{~mm}$ scan centered on $\mathrm{ONH}$ in all cases. Image quality was assessed and only OCTA images with a signal strength index $>40$ were included. Images with lines or gaps due to poor signal strength or motion artifacts (discontinuous vessel pattern or disc boundary) were retaken to be included in the study. Segmentation was done manually with different slabs to determine vascularity at different levels then average VDI (AVDI) was calculated.

The ONH was assessed in 4 levels: (1) The superficial Papillary level (VDI-1): extends from a point at level of internal limiting membrane to a point at level of outer boundary of inner plexiform layer (2) The deep papillary level (VDI-2): Extends from a point at level of outer boundary of inner plexiform layer to a point at the outer boundary of outer plexiform layer. (3) Outer retina level (VDI3 ): Extends from a point at level of outer boundary of outer plexiform layer to a point at the level of Bruch's membrane. (4) Choriodal level (VDI-4): Extends from the level of Bruch's membrane to 353 micometer below it.

\section{Vascular density index (VDI) measurement:}

Density map images gave qualitative data in which the more flow the more hot colors will be present and vice versa. For quantitative assessment, these images were processed using Image J program (IJ $1.46 \mathrm{r}$ edition). The program gave us quantitative data by determining VDI as percentage by taking $350 \times 350$ pixel images and converting it to binary images in which any flow has threshold could be detected as white color and those of very low or no flow could be detected as dark color [15] OCTA images are compared to those of normal control groups.

\section{Statistical analysis:}

All data analysis was performed using a statistical software package IBM SPSS version 20.0 [16]. Qualitative data were described using number and percent. Quantitative data were described using mean, standard deviation. Significance of the obtained results was judged at the 5\% level. Significance level was set at $p$-value $<0.5$. Chi-square test for categorical variables, to compare between different groups. Independent-Samples $t$-test and Paired-Samples $t$-test for normally quantitative variables, to compare between studied groups. 
Pearson coefficient to correlate between quantitative variables.

\section{Results}

As mentioned before, this study was performed on 15 eyes of 15 patients diagnosed as AO POAG and 20 eyes of 20 healthy age and sex-matched controls. Hence, this study had 2 groups; normal control group (20 eyes), AO POAG group (15 eyes). Only one eye per subject was included in the study and chosen randomly.

The sociodemographic data for age and gender distribution of both main 2 groups; normal control participants and glaucomatous patients were summarized and there were no significant differences between the groups regarding the age and gender distribution (Table 1).

Systemic evaluation of PR, SBP, DBP of all participants. By comparison with normal there were no statistically significant differences. As regard MAP there was also no significant difference. On the other hand, on comparing OPP of glaucoma patients with normal age matched controls, it was statistically significant different with $(p<0.001)$. Best Corrected Visual Acuity was tested for all patients and results were statistically significantly different. IOP measurements in glaucomatous patients were significantly different from normal. As regard CCT, there were no statistically significant differences. However, in comparing with normal, CCT measurements were higher in AO POAG group with the mean thickness was 567.45 \pm 18.63 um, 572 \pm 18.001 um (Table 2).

Visual field MD and PSD, vertical C/D ratio, rim area (RA), cup volume (CV) were significantly different in glaucoma group comparing with normal. The RNFLT measurements were significantly lower in AO POAG eyes with the mean of average RNFLT was $77.73 \pm 19.768$ um in AO POAG eyes. Average GCLT measurement was significantly lower in eyes with AO POAG $(p<0.001)$. All these glaucoma parameters are correlated with VDI in the glaucoma group with variation in the level with significant correlation but mostly VDI-1 (Table 3).

After processing of density map images of the 4 levels of segmentation for the 2 groups we could measure vascular density index (VDI). VDI measurements for glaucoma group are tabulated and compared with normal control group. These measurements are lower in glaucoma group. This decrease was marked with significant difference in choroidal level VDI4 $(p=0.009)$ followed by superficial papillary level VDI1 $(p=0.003)$ but dif- ference was not significant in VDI2 $(p=0.305)$ and VDI3 ( $p=0.859)$ (Table 4).

Table (1): Sociodemographic data for participants in the study.

\begin{tabular}{llll}
\hline Characteristics & & $\begin{array}{l}\text { AO POAG } \\
(\mathrm{n}=15 \text { eyes })\end{array}$ & $p$ \\
\hline Age (years) & $55.50 \pm 11.79$ & $58.53 \pm 11.42$ & 0.962 \\
Sex (M/F) & $9 / 11$ & $9 / 6$ & 0.419 \\
$\begin{array}{l}\text { Family history } \\
\quad \text { Positive/Negative) }\end{array}$ & $5 / 10$ & \\
$\begin{array}{l}\text { Topical medications } \\
\text { (Positive/Negative) }\end{array}$ & $6 / 9$ & \\
Duration & & \\
\hline
\end{tabular}

Data are presented as the mean \pm standard deviation.

$p$ for age: $p$-values for paired samples $t$-test for comparing between the two groups.

$p$ for sex: $p$-values for Chi square test for comparing between the two groups.

Table (2): Traditional glaucoma measurements in patients and controls.

\begin{tabular}{llll}
\hline Characteristics & $\begin{array}{c}\text { Normal } \\
(\mathrm{n}=20 \text { eyes })\end{array}$ & $\begin{array}{l}\text { AO POAG } \\
(\mathrm{n}=15 \text { eyes })\end{array}$ & \\
\hline PR $(\mathrm{bpm})$ & $73.65 \pm 10.95$ & $73.67 \pm 8.36$ & 0.996 \\
SBP $(\mathrm{mmHg})$ & $120.00 \pm 12.57$ & $115.00 \pm 11.26$ & 0.264 \\
DBP (mmHg) & $75.00 \pm 8.870$ & $76.67 \pm 6.17$ & 0.650 \\
MAP (mmHg) & $94.19 \pm 9.77$ & $92.91 \pm 7.64$ & 0.666 \\
OPP (mmHg) & $49.391 \pm 6$ & $38.34 \pm 8.65$ & $<0.001^{*}$ \\
BCVA & $0.93 \pm 0.12$ & $0.38 \pm 0.26$ & $<0.001^{*}$ \\
SE & $-0.68 \pm 1.1$ & $-2.48 \pm 1.85$ & $<0.001^{*}$ \\
IOP (mmHg) & $13.30 \pm 2.45$ & $23.60 \pm 6.69$ & $<0.001^{*}$ \\
CCT (um) & $567.45 \pm 18.6$ & $572.00 \pm 18.00$ & 0.454 \\
\hline
\end{tabular}

Table (3): Functional and structural parameters in the glaucoma and age matched normal controls.

\begin{tabular}{|c|c|c|c|}
\hline Parameters & $\begin{array}{c}\text { Normal } \\
(n=20 \text { eyes })\end{array}$ & $\begin{array}{l}\text { AO POAG } \\
(n=15 \text { eyes })\end{array}$ & \\
\hline $\mathrm{MD}(\mathrm{dB})$ & $0.59 \pm 1.25$ & $-9.065 \pm 6.81$ & $<0.001^{*}$ \\
\hline $\operatorname{PSD}(\mathrm{dB})$ & $2.65 \pm 0.36$ & $5.298 \pm 3.37$ & $0.001 *$ \\
\hline $\mathrm{C} / \mathrm{D}$ ratio & $0.29 \pm 0.08$ & $0.767 \pm 0.14$ & $<0.001 *$ \\
\hline $\mathrm{RA}\left(\mathrm{mm}_{3}{ }^{2}\right)$ & $1.678 \pm 0.26$ & $0.899 \pm 0.39$ & $<0.001 *$ \\
\hline $\mathrm{CV}\left(\mathrm{mm}^{\mathrm{s}}\right)$ & $0.18 \pm 0.18$ & $0.633 \pm 0.45$ & $<0.001 *$ \\
\hline ARNFLT $(m) L$ & $102.70 \pm 6.73$ & $77.73 \pm 19.77$ & $<0.001 *$ \\
\hline AGCLT ( & $91.34 \pm 4.59$ & $75.53 \pm 12.51$ & $<0.001 *$ \\
\hline
\end{tabular}

$p$-values for independent samples $t$-test for comparing between groups. $p$ : AO POAG vs Normal. *: Statistically significant at $p<0.05$.

- MD range $\left[-1.77_{-}(+3.29)\right]$ for Normal and $\left[-23.87_{-}(-2.55)\right]$ for AO POAG.

Table (4): Comparison of VDI measurements in the 4 levels in the 2 study groups.

\begin{tabular}{llll}
\hline VDI $(\%)$ & $\begin{array}{c}\text { Normal } \\
(\mathrm{n}=20 \text { eyes })\end{array}$ & $\begin{array}{c}\text { AO POAG } \\
(\mathrm{n}=15 \text { eyes })\end{array}$ & $p$ \\
\hline VDI-1 & $58.57 \pm 2.676$ & $53.01 \pm 5.919$ & $0.003^{*}$ \\
VDI-2 & $64.18 \pm 2.922$ & $62.19 \pm 6.84$ & 0.305 \\
VDI-3 & $47.16 \pm 4.037$ & $46.79 \pm 7.079$ & 0.859 \\
VDI-4 & $26.12 \pm 4.612$ & $21.58 \pm 4.972$ & $0.009^{*}$ \\
AVDI & $49.43 \pm 1.746$ & $45.892 \pm 3.954$ & $0.011 *$ \\
\hline
\end{tabular}

$p$-values for independent samples $t$-test for comparing between groups. $p$ : AO POAG vs Normal. *: Statistically significant at $p<0.05$. 


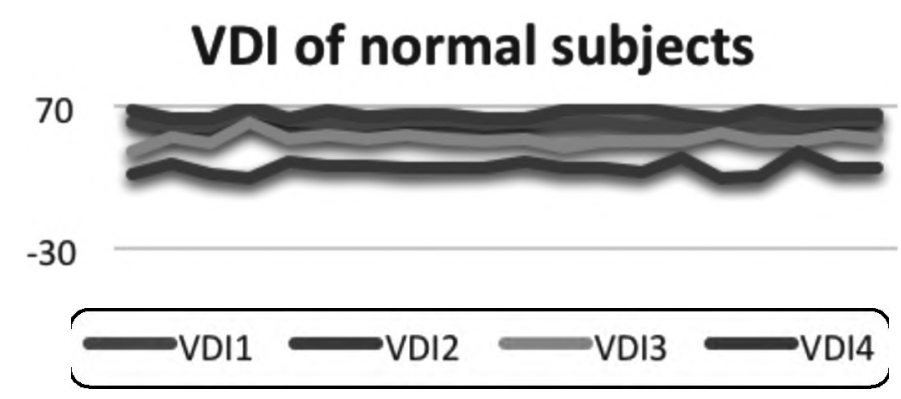

Fig. (1): Comparison of VDI measurements in the 4 levels in normal.
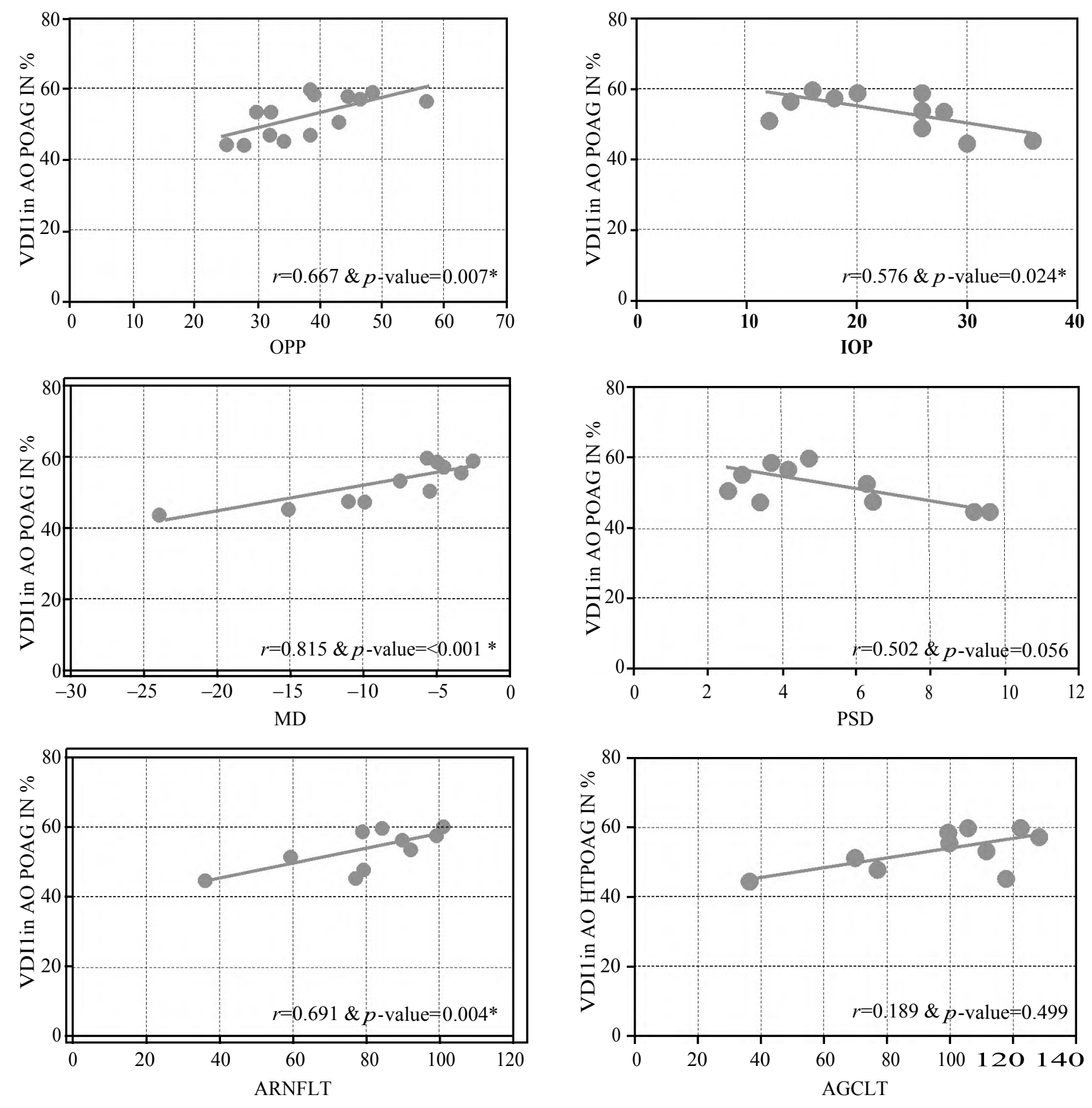

$r$ : Pearson correlation coefficient. $\quad *$ : Statistically significant at $p<0.05$.

Fig. (2): Scatter curves showing correlation between different glaucoma parameters \&VDI1 in the AO POAG. 
Fig. (3): $4.5 \times 4.5 \mathrm{~mm}$ OCTA of the right eye 45 years old female of normal control group: (A) OCTA of superficial papillary level: Normal dense peripapillary capillary plexus. (B) Density flow map of superficial papillary level. (C) Binary image of Density flow map of superficial papillary level with VDI1 $57.851 \%$. (D) OCTA of deep papillary level: Normal dense peripapillary capillary plexus. (E) Density flow map of deep papillary level. (F) Binary image of Density flow map of deep papillary level with VDI2 $67.54 \%$. (G) OCTA of outer retina level. $(\mathrm{H})$ Density flow map of outer retina level. (I) Binary image of Density flow map of outer retina level with VDI3 $49.362 \%$. (J) OCTA of choroidal level. (K) Density flow map of choroidal level. (L) Binary image of Density flow map of choroidal level with VDI4 27.323
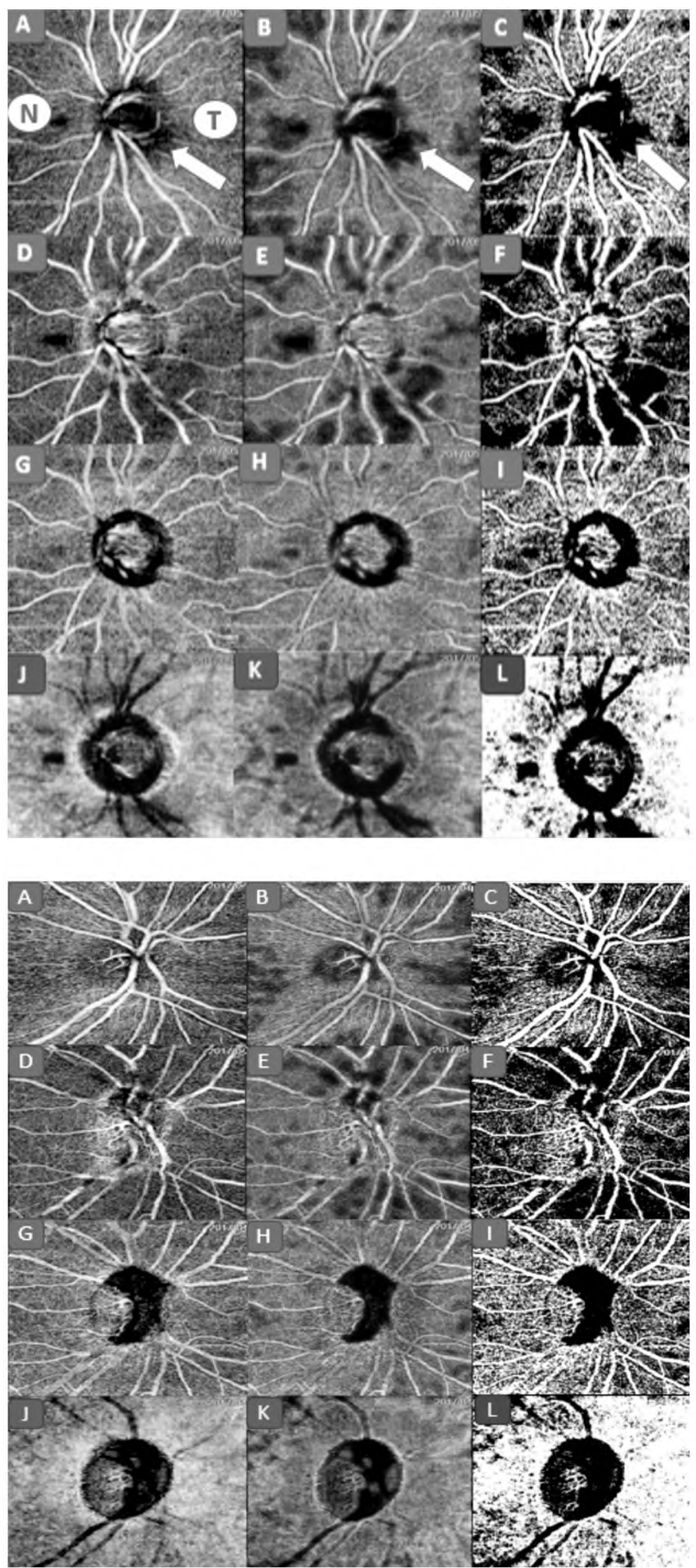

Fig. (4): $4.5 \times 4.5 \mathrm{~mm}$ OCTA of left eye of 50 years old male of mild POAG: (A) OCTA of superficial papillary level: diffuse capillary drop out of peripapillary capillary plexus all over OD marked infero-temporal area (yellow arrow). (B) Density flow map of superficial papillary level with cold blue colour in the corresponding areas of capillary drop out representing decreased vascular density i.e. ischemia (yellow arrow). (C) Binary image of Density flow map of superficial papillary level with VDI1 $55.894 \%$. (D) OCTA of deep papillary level: Scattered areas of capillary drop out in peripapillary capillary plexus. (E) Density flow map of deep papillary level. $(F)$ Binary image of Density flow map of deep papillary level with VDI2 $60.688 \%$. (G) OCTA of outer retina level. $(\mathrm{H})$ Density flow map of outer retina level. (I) Binary image of Density flow map of outer retina level with VDI3 $45.685 \%$. (J) OCTA of choroidal level. (K) Density flow map of choroidal level. (L) Binary image of Density flow map of choroidal level with VDI4 25.482\%. 


\section{Discussion}

In general, we noticed decreased VDI in glaucoma group in comparison with normal controls with AVDI significantly lowered with AO POAG as AVDI was reduced by $6.29 \%$. Hence, the markedly affected level was choroidal level in AO POAG that reduced by $17.37 \%$. This level represents the ciliary circulation the main blood supply of optic nerve head. This may give approve that ischemia in glaucoma is a primary cause not just secondary to elevated IOP.

Moreover, in qualitative assessment of vascular density maps with hot colour (red and orange) represent good perfusion areas while cold colours (blue) represent low perfusion i.e. ischemia maps of glaucoma patients showed marked decrease in optic disc and peripapillary vascular network present in maps of normal subjects. Also, this decrease correlated with disease severity.

In agreement with the present study results Liu, L., et al., [18] discovered a dense microvascular network around the disc that was visible on OCTA in normal eyes, this network was visibly attenuated globally and focally in glaucomatous eyes. Peripapillary flow index and peripapillary vessel density in glaucomatous eyes were lower than those in normal eyes $(p<0.001$ for both). Peripapillary flow index and peripapillary vessel density were highly correlated with visual field pattern standard deviation in glaucomatous eyes ( $p=0.001$ for both).

Moreover, Yarmohammadi, A., et al., [19] reported that age adjusted mean vessel density was significantly lower in OAG eyes compared with glaucoma suspects and healthy eyes. Vessel density had similar diagnostic accuracy to RNFLT measurements for differentiating between healthy and glaucoma eyes. These results suggest that OCTA measurements reflect damage to tissues relevant to the pathophysiology of OAG. In addition, Dastiridou A and Chopra V [20] also found that OCTA derived measurements have provided evidence for lower retinal vascular densities at $\mathrm{ONH}$, peripapillary and macula in pre perimetric-glaucoma and early-glaucoma, as well as, in more advanced glaucoma, in comparison to with normal eyes. However, $\mathrm{Xu}, \mathrm{H}$., et al., [21] said that the retinal perfused vessel density is significantly reduced in HTG and NTG eyes, and more prominently in the peripapillary region in NTG eyes.

In this study, many correlations were done to determine the relation between VDI and different important glaucoma parameters i.e. parameters for functional and structural glaucoma assessment. All these glaucoma parameters are correlated with VDI in the glaucoma group with variation in the level with significant correlation but mostly VDI-1.

In agreement with that, Leveque, P. M., et al., [22] detected changes in $\mathrm{ONH}$ vascularization in glaucoma patients using OCTA. In the glaucoma group, total and temporal ONH vessel density were reduced as compared with the control group. Moreover, showed significant correlation between RA and temporal and total ONH vessel density. Significant correlations were found between temporal and total ONH vessel density and RNFL, GCC, VF mean deviation, and visual field index. So, in glaucoma patients OCTA might detect reduced ONH blood vessel density that is associated with structural and functional glaucomatous damage. Moreover, Liu, L., et al., [23] described a significant correlation between vessel density and the VF parameters.

In conclusion, glaucoma patients showed markedly reduced $\mathrm{ONH}$ vascular density when compared with healthy controls using OCT angiography. The reduction in vascular density has a strong correlation with the functional, structural parameters. Hence, OCTA may be a promising technology in glaucoma management.

\section{References}

1- QUIGLEY H.A. and BROMAN A.T.: The number of people with glaucoma worldwide in 2010 and 2020 . British Journal of Ophthalmology, 90 (3): 262-7, 2006.

2- CAPRIOLI J. and COLEMAN AL.: Intraocular pressure fluctuation: A risk factor for visual field progression at low intraocular pressures in the Advanced Glaucoma Intervention Study. Ophthalmology, 115 (7): 1123-9. e3, 2008.

3- Pan Y, Varma R. Natural history of glaucoma. Indian Journal of Ophthalmology, 59 (Suppl. 1): S19.

4- MUSCH D.C., GILLESPIE B.W., LICHTER P.R., NIZIOL L.M., JANZ N.K. and INVESTIGATORS C.S.: Visual field progression in the Collaborative Initial Glaucoma Treatment Study: The impact of treatment and other baseline factors. Ophthalmology, 116 (2): 200-7. e1, 2009.

5- SCHMIDL D., GARHOFER G. and SCHMETTERER L.: The complex interaction between ocular perfusion pressure and ocular blood flow-relevance for glaucoma. Experimental. Eye Research, 93 (2): 141-55, 2011.

6- JANULEVICIENË I., SLIESORAITYTË I., SIESKY B. and HARRIS A.: Diagnostic compatibility of structural and haemodynamic parameters in open-angle glaucoma patients. Acta. Ophthalmologica., 86 (5): 552-7, 2008.

7- GHASEMI FALAVARJANI K. and SADDA S.R.: Optical coherence tomography angiography of the optic nerve head; current situation and future perspective. Yan Ke Xue Bao., 31 (3): 124-6, 2016. 
8- FALAVARJANI K.G. and SARRAF D.: Optical coherence tomography angiography of the retina and choroid; current applications and future directions. Journal of Current Ophthalmology, 29 (1): 1, 2017.

9- CHEN C-L., BOJIKIAN K.D., XIN C., WEN J.C., GUPTA D., ZHANG Q., et al.: Repeatability and reproducibility of optic nerve head perfusion measurements using optical coherence tomography angiography. Journal of Biomedical. Optics, 21 (6): 065002, 2016.

10- SPAIDE R.F., KLANCNIK J.M. and COONEY M.J.: Retinal vascular layers imaged by fluorescein angiography and optical coherence tomography angiography. JAMA Ophthalmology, 133 (1): 45-50, 2015.

11- YARMOHAMMADI A., ZANGWILL L.M., DINIZFILHO A., SUH M.H., MANALASTAS P.I., FATEHEE N., et al.: Optical Coherence Tomography Angiography Vessel Density in Healthy, Glaucoma Suspect, and Glaucoma Eyes OCT Angiography Vessel Density in Glaucoma. Investigative Ophthalmology \& Visual Science, 57 (9): OCT45 1-OCT9, 2016.

12- KAESER P., ORGÜL S., ZAWINKA C., REINHARD G. and FLAMMER J.: Influence of change in body position on choroidal blood flow in normal subjects. British Journal of Ophthalmology, 89 (10): 1302-5, 2005.

13- STANGA P.E., TSAMIS E., PAPAYANNIS A., STRINGA F., COLE T. and JALIL A.: Swept-source optical coherence tomography AngioTM (Topcon Corp, Japan): Technology review. OCT Angiography in Retinal and Macular Diseases. 56: Karger Publishers, p. 13-7, 2016.

14- RIVA C.E., GRUNWALD J.E. and PETRIG B.L.: Autoregulation of human retinal blood flow. An investigation with laser Doppler velocimetry. Investigative Ophthalmology \& Visual Science, 27 (12): 1706-12, 1986.

15- FERREIRA T. and RASBAND W.: Image J user guide. ImageJ/Fiji., 1, 2012.
16- NIE N., HULL C. and BENT D.: IBM statistical package for the social sciences (SPSS Version 20). Computer Software Chicago, IL: SPSS, 2011.

17- SUSANNA Jr. R. and VESSANI RM.: Staging glaucoma patient: Why and how? The Open Ophthalmology Journal, 3: 59, 2009.

18- LIU L., JIA Y., TAKUSAGAWA H.L., et al.: Optical coherence tomography angiography of the peripapillary retina in glaucoma. JAMA Ophthalmology, 133 (9): 1045$52,2015$.

19- YARMOHAMMADI A., ZANGWILL L.M., DINIZFILHO A., SUH M.H., MANALASTAS P.I., FATEHEE N., et al.: Optical Coherence Tomography Angiography Vessel Density in Healthy, Glaucoma Suspect, and Glaucoma Eyes. Investigative Ophthalmology \& Visual Science, 57 (9): OCT451-OCT9.

20- DASTIRIDOU A. and CHOPRA V.: Potential applications of optical coherence tomography angiography in glaucoma. Current Opinion in Ophthalmology, 29 (3): 226-33, 2018.

21- XU H., ZHAI R., ZONG Y., KONG X., JIANG C., SUN $\mathrm{X}$., et al.: Comparison of retinal microvascular changes in eyes with high-tension glaucoma or normal-tension glaucoma: A quantitative optic coherence tomography angiographic study. Graefe's Archive for Clinical and Experimental Ophthalmology, 256 (6): 1179-86, 2018.

22- LÉVÊQUE P-M., ZÉBOULON P., BRASNU E., BAUDOUIN C. and LABBÉ A.: Optic disc vascularization in glaucoma: Value of spectral-domain optical coherence tomography angiography. Journal of Ophthalmology, 2016.

23- LIU L., JIA Y., TAKUSAGAWA H.L., PECHAUER A.D., EDMUNDS B., LOMBARDI L., et al.: Optical coherence tomography angiography of the peripapillary retina in glaucoma. JAMA Ophthalmology, 133 (9): 1045-52, 2015. 


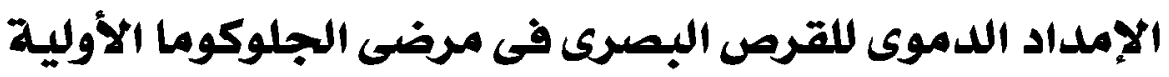

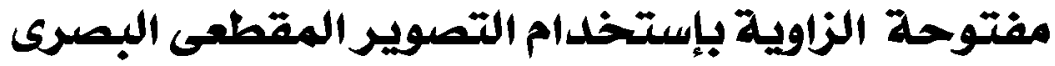

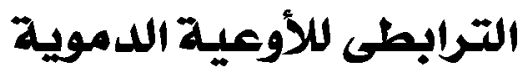

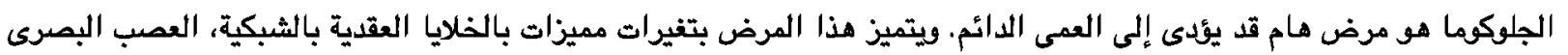

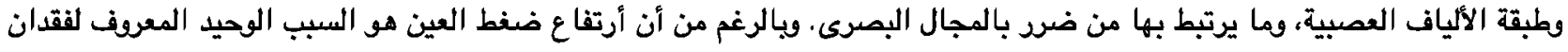

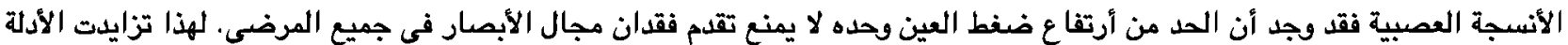

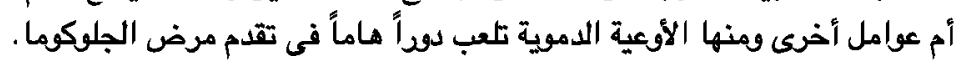

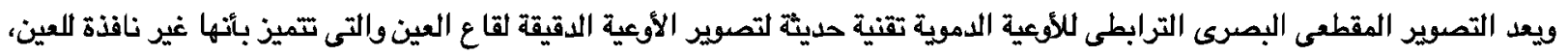

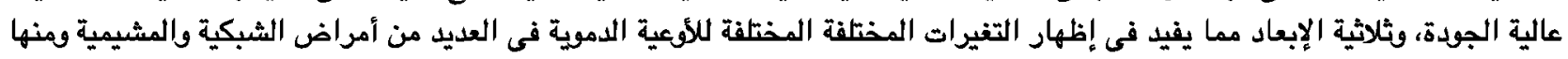
حالات الجلوكوما.

قاهت هذه الدراسة بهدف تقييم الأختافات في الإمداد الدموى للقرص البصرى فى عيون المرضى الذين يعانون من الجلوكوما الأولية مفتوحة الزاوية والعيفن الصحيحة بإستخدام التصوير المقطعى البصرى الإداد الترابطى للأوعية الدمعية.

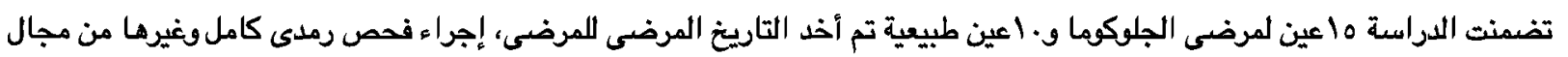

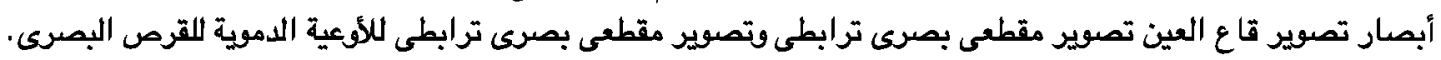

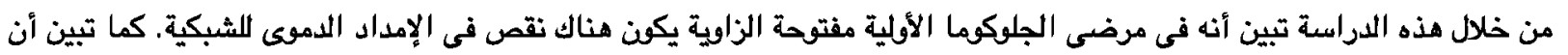

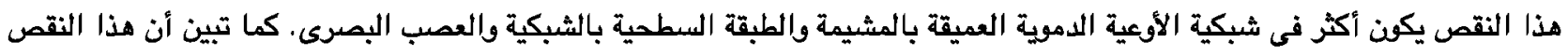

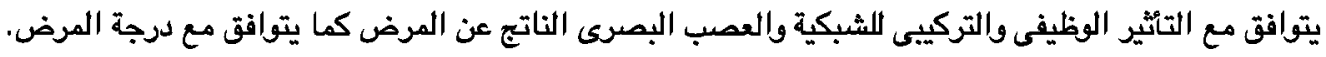

